\title{
Dysfunctional lens syndrome: a prospective review
}

\author{
Síndrome do cristalino disfuncional: uma revisão prospectiva
}

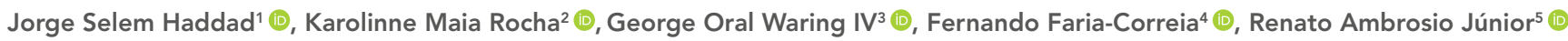

Department of Ophthalmology, Universidade Federal de São Paulo, São Paulo, SP, Brazil. ${ }^{2}$ Storm Eye Institute, Medical University of South Carolina, Charleston, SC, USA Waring Vision Institute, Mount Pleasant, SC, USA ${ }^{4}$ Universidade do Minho, Braga, Portugal ${ }_{5}^{5}$ Instituto de Olhos Renato Ambrósio, Rio de Janeiro, RJ, Brazil.

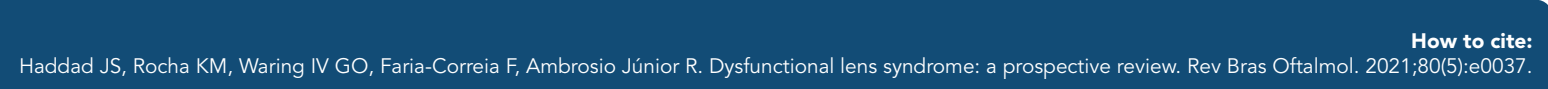

Haddad JS, Rocha KM, Waring IV GO, Faria-Correia F, Ambrosio Júnior R. Dysfunctional lens syndrome: a prospective review. Rev Bras Oftalmol. 2021;80(5):e0037.

https://doi.org/10.37039/1982.8551.20210037

Keywords:

Dysfunctional lens syndrome; Aberrations; Presbyopia; Cataract; Lens, crystalline

Descritores:

Síndrome disfuncional do cristalino; Aberrações, Presbiopia; Catarata; Cristalino

Received on: Feb 28, 2021

Accepted on: Jun 26, 2021

Corresponding Author: Storm Eye Institute, Medical University of South Carolina 167 Ashley Ave, Charleston, South Carolina, United States Phone: (843) 792-2385 Fax: (843) 881-6454

E-mail: jshaddad2@hotmail.com

Institution: Universidade Federal de São Paulo, São Paulo, SP, Brazil.

Conflict of interest: Dr. Haddad, Dr. Faria-Correia and Dr. Rocha have no financial or proprietary interest in any product mentioned herein. Dr. Ambrosio and Dr. Waring are consultants for Oculus ${ }$, Wetzlar, Germany.

Financial support: no financial support for this work.

\section{ABSTRACT}

The term dysfunctional lens syndrome has gained acceptance in the field and encompasses natural changes due to aging of crystalline lens. The evolution of diagnostic devices has been a key factor in better staging, understanding and characterizing of these degenerative changes. Even with these technological advances and the use of subjective classifications, such as the classic Lens Opacities Classification System, an objective staging of early dysfunctional lens syndrome has yet to be established. Ocular wavefront aberrometry and objective scatter index, associated with Scheimpflug backscatter densitometry, have proven instrumental in detecting early dysfunctional lens syndrome. Staging of early dysfunctional lens syndrome has been proposed in the literature, but no classification has been recognized worldwide. The purpose of this literature review is to assess the current state of dysfunctional lens syndrome from a technological perspective and propose a new staging system to assist surgeons in making surgical decisions.

\section{RESUMO}

O termo "síndrome disfuncional do cristalino" tem sido mais aceito na área e engloba mudanças naturais devido ao envelhecimento do cristalino. A evolução dos dispositivos diagnósticos tem sido fator fundamental para melhor estadiamento, compreensão e caracterização dessas alterações. Mesmo com esses avanços tecnológicos e o uso de classificações subjetivas, como o Lens Opacities Classification System, um estadiamento objetivo da síndrome disfuncional do cristalino precoce ainda não foi estabelecido. A aberrometria ocular total e o índice de superfície ocular, associado à densitometria de Scheimpflug, mostraram-se instrumentais na detecção da síndrome disfuncional do cristalino precoce. Embora estadiamentos precoces de síndrome disfuncional do cristalino tenham sido propostos na literatura, nenhum foi reconhecido mundialmente até o momento. O objetivo desta revisão de literatura é avaliar o estado atual da síndrome disfuncional do cristalino a partir de uma perspectiva tecnológica, e propor um novo sistema de estadiamento para auxiliar os cirurgiões na tomada de decisões cirúrgicas.

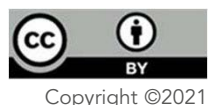




\section{INTRODUCTION}

Dysfunctional lens syndrome (DLS) is characterized by progressive changes in the crystalline lens, impacting the patient's quality of accommodation and of vision. Due to its broad definition, this syndrome has been addressed mainly by the evolution of imaging methods and early diagnosis.

With aging, changes in the crystalline lens induce gradual loss of transparency, increase in density, and start of presbyopia. ${ }^{(1)}$ Stage one of DLS is often observed in patients aged between 40 and 50 years with accommodation loss, and relatively low light scatter. In the second stage (usually presented in patients aged $>50$ years), increased ocular scatter and higher-order aberrations (HOA), decreased contrast sensitivity, and lens opacity occurs. The third stage involves moderate to clinically significant cataract, and surgical procedures may be required..$^{(2,3)}$

The Lens Opacities Classification System (LOCS) is the most accepted method for staging crystalline lens transparency by clinical professionals and surgeons. ${ }^{(4,5)}$ Several improvements in imaging diagnosis have been made, including Scheimpflug densitometry, which provides an objective measure of lens density. Similarly, the objective ocular scatter index (OSI), provided by double-pass technology, can objectively quantify forward scatter related to retinal image quality. ${ }^{(6)} \mathrm{Also}$, in recent DLS reports, this parameter was highly correlated with the Scheimpflugbased densitometry measurements. ${ }^{(2)}$

This literature review proposes a new staging for DLS that includes the diagnostic tools and terminology used to stage the disease. This new staging provides ophthalmologists with decisive criteria for approaching a patient with DLS in the course of their evolution.

\section{CONSIDERATIONS REGARDING THE CRYSTALLINE LENS}

\section{Lens accommodation}

Accommodation of the lens results from changes in its shape, with alteration in its curvature and thickness, modifying its convergence power and thereby the eye dioptric power. Helmholtz's best-known theory proposes that the ciliary muscle contracts and produces a relaxation of the zonular fibers, increasing the thickness and curvature of the lens and, consequently, increasing its dioptric power. ${ }^{(1)}$ It is commonly known that around the age of 40 years, it becomes difficult for the patient to focus on nearby objects. According to this theory, when the zonules are relaxed, the crystalline lens can no longer change its shape; therefore, presbyopia is a condition that can only be reversed by replacing the elasticity of the capsule or the lens.

\section{Higher-order aberrations}

Higher-order aberrations are refractive errors that are not corrected by sphere and cylinder corrections. They are defined as wavefront deviations that cannot be easily compensated by conventional means, such as contact lenses, spectacles, and laser vision correction. They also include errors in the eye optical system, which can deteriorate the quality of retinal image. HOA changes with age are one of the main mechanisms that cause presbyopia. As previously described in the literature, the crystalline lens in its relaxed state has a negative spherical aberration (SA), counterbalanced by the positive value of the corneal surface. ${ }^{(7)}$ This counterbalance occurs until the age of 45 , where the turning point for aberration compensation seems to shift. ${ }^{(8)}$ This shift is associated with an increase of coma, and a positive SA attributed to aging of the crystalline lens. ${ }^{(9)}$

\section{Objective scatter index}

With aging, the appearance of optical flaws in the optical medium generally results in light dispersion. Two methods can analyze this effect: forward scattering, which examines the light scattered into the retina; and backward-scattering, which quantifies the light being scattered backward.

One way to objectively measure the OSI and quantify the intraocular light scattering is by examining the double-pass wavefront (Optical Quality Analysis System, OQAS, HD Analyzer, Visiometrics, Terrasa, Spain). This device directs a near-infrared light monochromatic 780-nm laser beam point source on the retina. The HD Analyzer measures forward scatter by employing a double-pass technique as light passes through the ocular interfaces resulting from localized deviations of light, in addition to aberrations in light reflected from the retina. ${ }^{(8)}$ The instrument has a fixed diameter entrance pupil of $2 \mathrm{~mm}$ and a variable diameter exit pupil between 3 and 6 $\mathrm{mm}$ controlled by the operator. The spatial light distribution of a point source imaged on the retina is described by the point spread function (PSF), which is calculated by the device as a mean of six scans. The OSI is computed based on the relative intensity divided by ten between the central area within 1 minute of arc and a peripheral ring between 12 minutes and 20 minutes of arc of the double-pass image of the eye. The greater the aberrations and intraocular scatter, the greater the spread of the PSF, and the greater the OSI. 


\section{A staging proposal for dysfunctional lens syndrome}

The term "dysfunctional lens syndrome" has recently been used to describe early cataract and presbyopia with little to no sign of visual acuity loss. ${ }^{(10)}$ There have been several attempts to classify DLS, but none have been unanimously recognized among ophthalmologists. Rocha and Waring ${ }^{(2)}$ defined DLS as a loss of accommodation (stage 1), an increase in HOA and forward scatter of light, decreased contrast sensitivity, and early lens opacities (stage 2), and clinically significant cataract with decreased functional vision (stage 3). Similarly, Fernández et al. ${ }^{(3)}$ defined stage one as presbyopia itself in patients aged 42 to 50 years, and stages 2 and 3 are defined by an increase in ocular scatter. Despite differences in the proposed staging systems, it is widely accepted the crystalline lens undergoes progressive changes over the years, creating problems with daily activities for patients.

In our proposed staging system for DLS, the first stage is characterized by the initial loss of accommodation
(Table 1). Usually, at this early stage, the patient needs an addition power up to $+2.25 \mathrm{D}$ (Figure 1). In the second stage, there is a marked progressive loss of accommodation, requiring an addition of more than $+2.50 \mathrm{D}$. In the third stage, the appearance of a mild cataract is observed, with loss of transparency of the lens, causing loss of vison quality (Figure 2). In the fourth stage, a decrease in contrast sensitivity and decreased visual acuity in the Snellen table is observed, with vision worse than $20 / 30$ with a moderate decrease in contrast sensitivity. Finally, in the fifth and last stage, moderate cataract is observed, with significant visual loss in the Snellen high-contrast acuity chart and vision equal to or worse than 20/50. An example of this stage is shown in Figure 3.

Table 1. Staging proposal for dysfunctional lens syndrome

Stage I - Slight loss of accommodation: initial presbyopia (addition up to +2.25)
Stage II - Increased loss of accommodation (addition $>+2.50$ )
Stage III - Reduced quality of vision (contrast sensitivity; Straylight)*
Stage IV - Reduced visual acuity with high contrast (Snellen $<20 / 30$ )
Stage V - Increased loss of visual acuity due to cataract

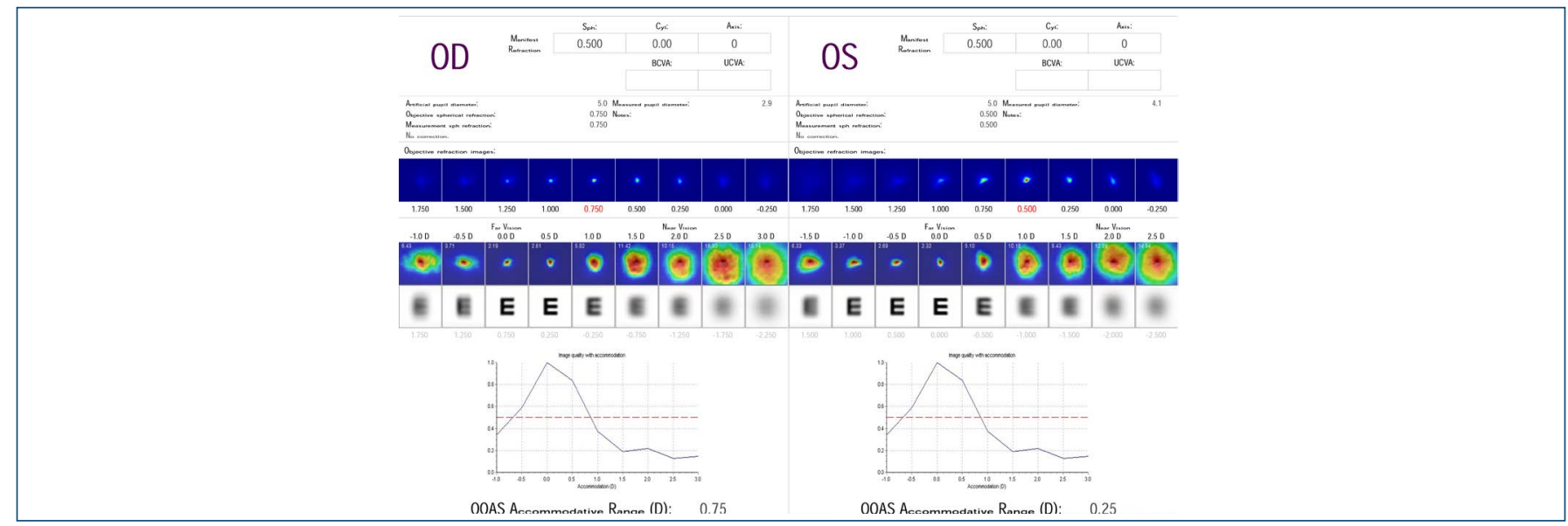

Figure 1. Double-pass imaging system measuring a stage 1 patient showing decreased image quality with accommodation change.

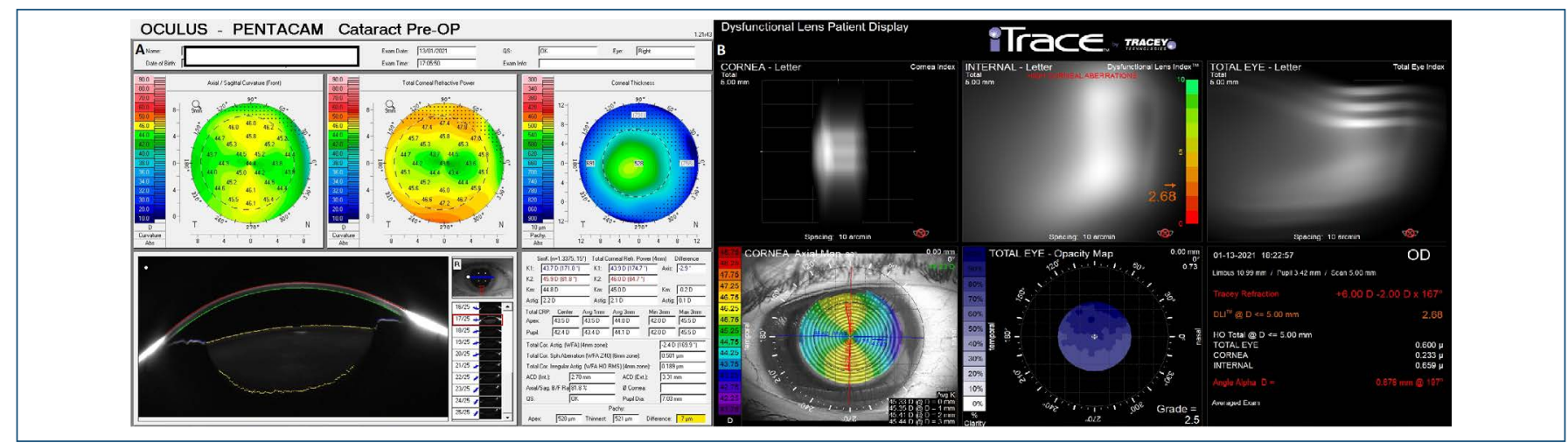

Figure 2. (A) iTrace (Tracey Technologies; USA) with objective dysfunctional lens syndrome study. In the aberrometry exam, it is verified that the dysfunctional lens index has a score of 2.68 (scale of zero to ten, ten relative to the best optical performance staging for the lens). The aberrometry system performs a vision simulation ("Total Eye - Letter"). (B) Lens densitometry by Scheimpflug image with Pentacam (Oculus, Germany). There are signs of hyperreflectivity at the level of the corticonuclear cataract. In this clinical case, visual complaints are derived from the presence of cataracts in stage 3. 


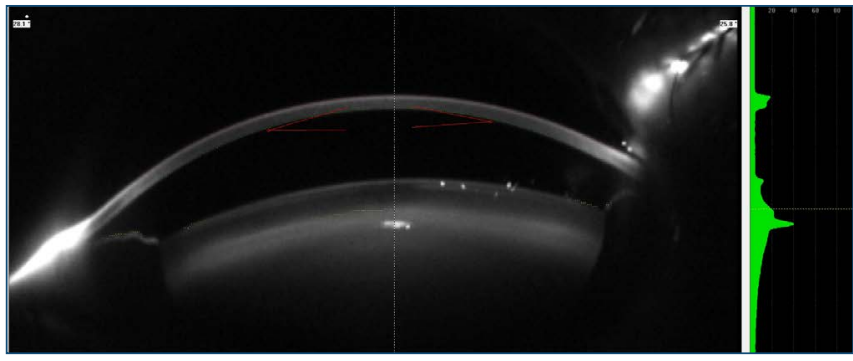

Figure 3. Lens densitometry by Scheimpflug image in a stage 5 patient. Note the hyperreflectivity at the nuclear lens. In this clinical case, moderate cataract is observed, with significant visual loss in the Snellen high-contrast acuity chart and vision equal to or worse than 20/50.

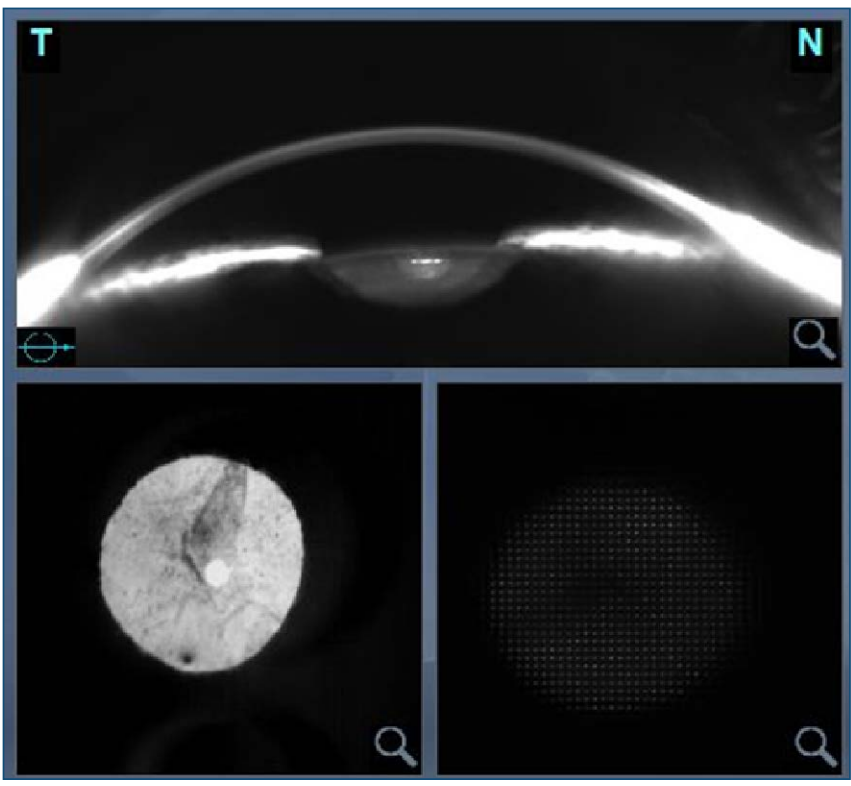

Figure 4. Mild cataract documentation with the Wave Analyser 700+ (WAM700+; Essilor, France) with Scheimpflug image, retroillumination and Hartmann-Shack centroids.
Clinicians prefer evidence-based diagnosis, and the early diagnosis of DLS is based on advanced imaging technology. Despite its limitations, the LOCS III is the most used subjective system for cataract grading. ${ }^{(11)}$ Variables that influence the final score comprise training level of professionals ${ }^{(12)}$ and slit-lamp settings. ${ }^{(13)}$ Additionally, subjective inter-observer variability occurs when the crystalline lens is staged. ${ }^{(14)}$ Conversely, Scheimpflug imaging allows the ophthalmologist to both grade lens densitometry and improve phacodynamics. ${ }^{(15)}$ The literature has reports of several attempts to standardize lens densitometry, but there is no consensus on this point. ${ }^{(16)}$ For example, Faria-Correia et al. observed a significant association between DLS and cataract surgery using the Scheimpflug-measured average density without including forward scatter measurements. ${ }^{(17)}$

Considering forward scatter analysis, the OSI parameter can measure and quantify the intraocular scattering of light using devices, such as the double-pass HD Analyzer. ${ }^{(6)}$ A correlation between OSI and clinical evaluation (such as LOCS III) has been previously reported, albeit with limitations. The central pupil area (4 mm), subscapular cataract, and cortical cataract are some of these limitations, and may not be accurate when correlating the two variables. ${ }^{(18-20)}$

Retroillumination can be integrated to Scheimpflug imaging and other multimodal approaches, like ocular wavefront with Hartmann-Shack, as in the WAV 700+ (Essilor, France; Figure 4) and Pentacam AXL/WAVE (Oculus, Germany; Figure 5).

Waring et al. ${ }^{(2)}$ reported an accurate correlation between Scheimpflug densitometry and OSI in lower grades

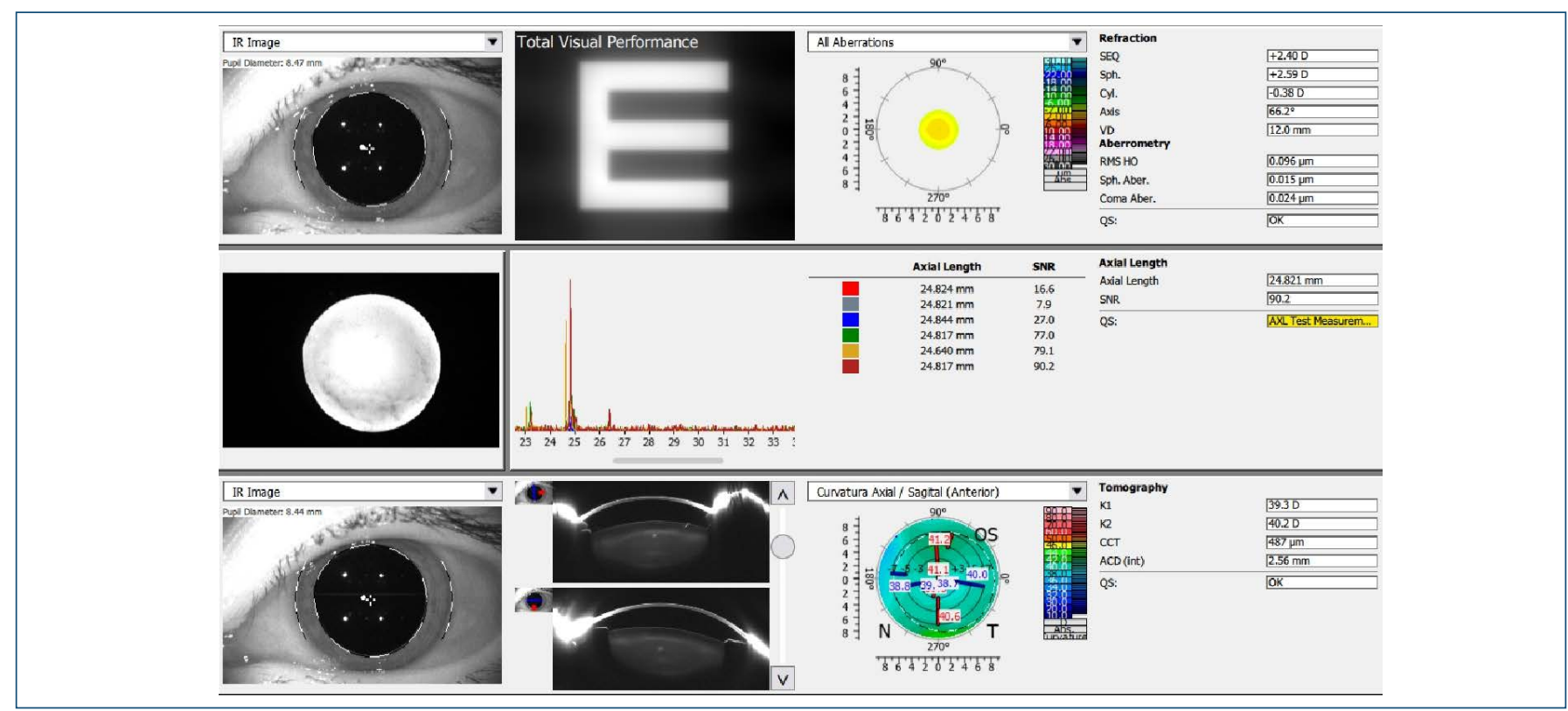

Figure 5. Mild cataract documentation with the Pentacam AXL/Wave, including optical wavefront, retroillumination, corneal tomography, axial length and Scheimpflug imaging. 
of nuclear opalescence cataract. Notably, the authors reported more variability between both devices in higher grades of nuclear opalescence in LOCS III.

It is important to acknowledge the criteria for carrying out lens exchange diverge in different parts of the world. In Spain, there is a cutoff value of 20/50 visual acuity to justify the surgical lens replacement. In the United States, the patient must have 20/40 vision or worse and/or problems with their "activities of daily living" before qualifying for cataract surgery. There are no established criteria for cataract surgery worldwide; however, some authors recommend surgery when DLS increases to stage 4 .

The criteria by which some clinicians consider refractive lens exchange as a treatment for presbyopia include stage 2 with increased ocular scatter ${ }^{(2,3)}$, high myopia $^{(21)}$, hyperopia ${ }^{(22)}$, and patients with stage 1 associated with reduced visual quality under low light conditions. ${ }^{(23)}$ However, this decision must consider the risks in performing cataract surgery, including retinal detachment, macular edema, and choroidal effusion. ${ }^{(22)}$ Importantly, there is a percentage increase in these complications when associated with high myopia and high hyperopia. ${ }^{(22,23)}$

\section{CONCLUSION}

While the concept of dysfunctional lens syndrome is now commonly recognized, a standard and universally accepted staging system has yet to be established. In the staging system proposed in this review, transparency and presbyopia are independent factors, but in advanced stages, they can occur concomitantly. This new staging is based on our current understanding of dysfunctional lens syndrome, which has benefitted from technological advances in diagnostic devices. Furthermore, this new staging and staging system may assist surgeons in making surgical decisions for DLS patients.

\section{REFERENCES}

1. Santos-Neto E, Alves MR. New concepts in accommodation and presbyopia. Rev Bras Oftalmol. 2011;70(5):306-11.

2. Waring GO, Rocha KM. Characterization of the dysfunctional lens syndrome and a review of the literature. Curr Ophthalmol Rep. 2018;6(4):249-55

3. Fernández J, Rodríguez-Vallejo M, Martínez J, Tauste A, Piñero DP. From presbyopia to cataracts: a critical review on dysfunctional lens syndrome. J Ophthalmol. 2018;2018:4318405.
4. Chylack LT Jr, Leske MC, McCarthy D, Khu P, Kashiwagi T, Sperduto R. Lens Opacities Classification System II (LOCS II). Arch Ophthalmol. 1989;107(7):991-7.

5. Chylack LT Jr, Wolfe JK, Singer DM, Leske MC, Bullimore MA, Bailey IL, et al. The Lens Opacities Classification System III. The Longitudinal Study of Cataract Study Group. Arch Ophthalmol. 1993;111(6):831-6.

6. Artal P, Benito A, Pérez GM, Alcón E, Casas A, Pujol J, et al. An objective scatter index based on double-pass retinal images of a point source to classify cataracts. PloS One. 2011;6(2):e16823-e16823.

7. Smith G, Cox MJ, Calver R, Garner LF. The spherical aberration of the crystalline lens of the human eye. Vision Res. 2001;41(2):235-43.

8. Artal P, Berrio E, Guirao A, Piers P. Contribution of cornea and interna surfaces to the change of ocular aberration with age. Opt Soc Am A Opt Image Sci Vis. 2002;19(1):137-43.

9. Alió JL, Schimchak P, Negri HP, Montés-Micó R. Crystalline lens optical dysfunction through aging. Ophthalmology. 2005;112(11):2022-9.

10. Waring GO IV RK, Durrie DS, Thompson VM. Use of dysfunctional lens syndrome grading to guide decision making in the surgical correction of presbyopia. presented at: ASCRS/ASOA Symposium \& Congress; May 10, 2016; New Orleans, LA.

11. Grewal DS, Brar GS, Grewal SP. Correlation of nuclear cataract lens density using Scheimpflug images with Lens Opacities Classification System III and visual function. Ophthalmology. 2009;116(8):1436-43.

12. Karbassi M, Khu PM, Singer DM, Chylack LT Jr. Evaluation of lens opacities classification system III applied at the slitlamp. Optom Vis Sci. 1993;70(11):923-8.

13. Kirwan JF, Venter L, Stulting AA, Murdoch IE. LOCS III examination at the slit lamp, do settings matter? Ophthalmic Epidemiol. 2003;10(4):259-66.

14. Bullimore MA, Bailey IL. Considerations in the subjective assessment of cataract. Optom Vis Sci. 1993;70(11):880-5

15. Faria-Correia F, Lopes BT, Ramos IC, Monteiro T, Franqueira N, Ambrósio R Jr. Application of different Scheimpflug-based lens densitometry methods in phacodynamics prediction. Clin Ophthalmol. 2016;10:609-15.

16. Weiner X, Baumeister M, Kohnen T, Bühren J. Repeatability of lens densitometry using Scheimpflug imaging. J Cataract Refract Surg. 2014;40(5):756-63.

17. Faria-Correia F, Ramos I, Lopes B, Monteiro T, Franqueira N, Ambrósio $\mathrm{R}$, Jr. Correlations of objective metrics for quantifying dysfunctional lens syndrome with visual acuity and phacodynamics. J Refract Surg. 2017;33(2):79-83.

18. Vilaseca M, Romero MJ, Arjona M, Luque SO, Ondategui JC, Salvador $A$, et al. Grading nuclear, cortical and posterior subcapsular cataracts using an objective scatter index measured with a double-pass system. Br J Ophthalmol. 2012;96(9):1204-10.

19. Paz Filgueira C, Sánchez RF, Issolio LA, Colombo EM. Straylight and visual quality on early nuclear and posterior subcapsular cataracts. Curr Eye Res. 2016:41(9):1209-15

20. Cabot F, Saad A, McAlinden C, Haddad NM, Grise-Dulac A, Gatinel D. Objective assessment of crystalline lens opacity level by measuring ocular light scattering with a double-pass system. Am J Ophthalmol. 2013;155(4):629-635, 635.e1-2.

21. Horgan N, Condon PI, Beatty S. Refractive lens exchange in high myopia: long term follow up. Br J Ophthalmol. 2005;89(6):670.

22. Alió JL, Grzybowski A, Romaniuk D. Refractive lens exchange in modern practice: when and when not to do it? Eye Vis (Lond). 2014;1:10-10.

23. Ferrer-Blasco T, García-Lázaro S, Albarrán-Diego C, Pérez-Vives C, MontésMicó R. Contrast sensitivity after refractive lens exchange with a multifocal diffractive aspheric intraocular lens. Arq Bras Oftalmol. 2013;76(2):63-8. 